\title{
NLM and the IAIMS Initiative: Cross- Institutional Academic/Advanced Systems Contributing to the Evolution of Networked Information and Resources
}

\author{
Nancy M. LORENZI Ph.D. ${ }^{\mathrm{a} 1}$ and William W. STEAD M.D. ${ }^{\mathrm{a}, \mathrm{b}}$ \\ ${ }^{a}$ Vanderbilt University, School of Medicine, Department of Biomedical Informatics \\ ${ }^{b}$ Vanderbilt University School of Medicine, Department of Medicine
}

\begin{abstract}
The Integrated Academic/Advanced Information Systems (IAIMS) program began in 1983 and was based on a study by the Association of American Medical Colleges (AAMC). Donald A.B. Lindberg M.D. was a member of the AAMC Advisory Committee. The U.S. National Library of Medicine (NLM) grants for IAIMS were initiated in 1984 the same year Dr. Lindberg became Director of the NLM. This chapter presents an overview of IAIMS and its progression through three stages with Dr. Lindberg's leadership.
\end{abstract}

Keywords. IAIMS, Integrated Information, Integrated Resources, National Library of Medicine (NLM), Medical Libraries, Association of American Medical Colleges (AAMC)

In memory of Richard T. West, MLS, IAIMS Program Officer

\section{Introduction}

The Integrated Academic Information Management Systems (IAIMS) initiative was a significant strategy by the U.S. National Library of Medicine (NLM) to strengthen medical libraries and librarians and their respective roles. Later in the evolution of IAIMS the word "Academic" was changed to "Advanced" to recognize the applicability to both clinical and academic components of health science centers and the importance of advanced technologies.

To understand the role of IAIMS in information management and the role of Donald A.B. Lindberg, M.D.'s leadership it is critical to understand the background and context of the IAIMS effort. This chapter begins by sketching the environmental context of medical libraries in the 1960's and 1970's including passage of the Medical Library Assistance Act and establishment of the Lister Hill Center for Biomedical Communication within the NLM. Section three describes the emergence of the concept of integrating information in response to this rapidly changing environment and sets the stage for the NLM's launch of the IAIMS program in 1983. Section four presents the evolution of IAIMS under Dr. Lindberg's leadership from the initial concept to wide-

\footnotetext{
${ }^{1}$ Corresponding Author: Nancy M. Lorenzi, PhD, 2525 West End Avenue, $14^{\text {th }}$ Floor Suite 1475, Nashville TN 37203-8556, USA; E-mail: nancy.lorenzi@vumc.org.
} 
spread implementation. It highlights Dr. Lindberg's use of strategic planning to catalyze implementation of concepts and strategies. Section five outlines the influence of the IAIMS program on the organizational fabric of participating academic health science centers and in nurturing national scale collaboration and consortia activities. Section six describes the impact of Dr. Lindberg's leadership on IAIMS and the impact of IAIMS on Dr. Lindberg as Director of the NLM. The chapter closes by reporting four enduring lessons from the IAIMS program.

\section{Environmental Context of Medical Libraries before IAIMS}

In 1963, Harold Bloomquist, MLS, Assistant Librarian at the Harvard University Medical Library conducted a study of the status and needs of 86 medical school libraries for the National Library of Medicine. His findings indicated that investment in medical libraries had not kept pace with growth of research, specialization, and multi-disciplinary science. He highlighted the profound effect of these changes and growth rates on biomedical communication and reported that scientists and other library users "encountered so many difficulties in working with the traditional library system that they have tended to neglect the use of formal published information sources and have developed a number of other devices to obtain the required information." The report recommended federal support of "the essential bibliographic apparatus needed in medical research" with NLM taking national leadership, including "a system of regional reservoir libraries", programs for training librarians and matching grants for library construction [1].

\subsection{The Medical Library Assistance Act (MLAA) and the National Library of Medicine (NLM)}

The U.S. Congress passed the Medical Library Assistance Act (MLAA) in 1965. This legislation enabled the NLM to initiate programs to assist the nation's medical libraries and to develop a medical library network with the establishment of regional medical libraries to link the NLM with local institutions. This act catalyzed construction or expansion of 86 health science libraries from 1966 to 1975 [2].

The Lister Hill Center for Biomedical Communication was established within the NLM in 1968 by Senate Joint Resolution to develop networks and information systems to improve health education, medical research and the delivery of health services. The question of content, what messages shall be communicated and who is responsible for determining what these messages shall be, was central to any plans for the new center. NLM contracted with the Association of American Medical Colleges (AAMC) to provide recommendations about content development and furthering relations between the NLM and the academic medical community. The Steering Committee, chaired by Eugene A. Stead Jr., MD. consulted over 100 individuals and visited ten medical schools. The 1971 report recommended that "The Lister Hill Center should have as its eventual goal the development of education methods which will render obsolete the current systems of libraries, textbooks, medical school curricula, and total dependence on memory and pattern recognition in clinical decision making and problem solving." It also recommended the Center fund approximately ten regional medical divisions of computer 
science in medical centers with strong university programs to develop needed manpower [3].

\section{The Association of American Medical Colleges Study: Toward the Concept of Integrating Information}

In 1979, the National Library of Medicine contracted with AAMC to explore the future of librarianship, with the question of technology looming on the horizon [4]. The report of that study, co-authored in 1982 by Nina Matheson, M.L.S., and John Cooper, M.D., was titled Academic Information in the Academic Health Sciences Center: Roles for the library in information management [5].

They reported that academic health science centers "information support systems are fragmented mixtures of single function, manual, and computer-based files that can neither communicate nor exchange information effectively." They recommended that: academic centers implement a network that facilitates the flow of recorded knowledge throughout their institutions with the "library as a primary node"; professional associations link academic, administrative and organization information bases to hospitals and individual practitioners; and industry, foundations and federal agencies develop prototype network systems and programs that encourage the rapid integration of information technology (IT) in the learning and practice of health professions, programs that attract and retain qualified people in medical information and knowledge-base development in academic centers.

The study had an advisory committee for direction and advice. Since Dr. Lindberg had been a member of the Biomedical Library Review Committee (BLRC) in the late 1970's, he was invited to be a member of the advisory committee by the AAMC. Dr. Lindberg understood the issues outlined in the AAMC's report. The report provided a foundation that led to the National Library of Medicine under his leadership to continue and enhance the IAIMS strategy.

\section{The National Library of Medicine: IAIMS Initiative}

Responding to the report from the AAMC, the National Library of Medicine embarked on a long range Integrated Academic Information Management System (IAIMS) prototype development program to develop models for designing and effectively managing information at large-scale for health care institutions.

The goal was to catalyze development of programs and products so that the needed and appropriate information would be available where and when required to support research, education and/or patient care. IAIMS placed health science institutions in the forefront of information systems integration and communications networking. In 1992, Dr. Lindberg wrote "IAIMS has been a significant initiative and notable success in developing organizational mechanisms to manage the knowledge of medicine [6]."

This chapter describes the evolution of IAIMS from its initial concept to widespread implementation in three stages. Throughout the stages strategic planning "drove" the implementation concepts and strategies. The three stages are: Exploring, Clarifying and Expanding, and Mainstreaming. 


\subsection{Exploring; IAIMS First Generation}

In 1983, the NLM issued a request for proposals to conduct institution-wide strategic planning for information resources management. Four contracts were issued to Columbia University, Georgetown University, University of Maryland at Baltimore and the University of Utah. Later that year, the Medical Library Association published a special issue to familiarize the health science library community with the AAMC report [7]. The multiple articles explored an overview of IAIMS, as well as implications for planning, access, delivery and the role of libraries and librarians [8-10].

In 1984, when Dr. Lindberg became Director of the National Library of Medicine, he established a long-range planning group for the NLM. That group was organized into 5 panels: (1) Building and Organizing the Library's Collection: Robert M. Hayes, PhD (2) Locating and Gaining Access to Medical and Scientific Literature: Nancy M. Lorenzi, PhD (3) Obtaining Factual Information from Data Bases: Ruth Davis, PhD. (4) Medical Informatics: Edward H. Shortliffe, MD PhD, (5) Assisting Health Professions Education Through Information Technology: G. Octo Barnett, MD

Panels 2 and 4 included goals that impacted NLM's IAIMS strategy. Panel Two supported NLM's efforts "to develop technologies related to knowledge-based systems and recommended improvement in disseminating biomedical information." Panel Two stressed that "IAIMS projects created effective models and that IAIMS provides an effective process and framework for implementation [11]."

The Panel Four report stressed that in the future computers will be routine in health care. The report indicated that the 1AIMS program had led to an increased awareness of the clinical role of computers and that individual academic institutions had begun to grapple with issues of instructional and research computing, administrative data processing, information dissemination, and communication within the medical center, the need for expertise in the area of medical informatics has become increasingly evident to administrators [12].

After issuing the initial contracts, NLM switched to IAIMS grant mechanisms, encompassing three phases: planning, model development to test to evaluate the results of the planning process, and implementation. The IAIMS grantee institutions completed demonstration projects to improve information access and utilization. These early efforts led to new capabilities for medical informatics to support the health care system.

In October 1984, NLM held a symposium to introduce the efforts of the four contracts recipients [13]. Dr. Lindberg introduced the symposium with his hope for the future: "a lot of what we will hear today has to do more with arrangements between people and the managing of institutions than it has to do with the technology of the systems...technology is better now... attitudes are different from those of twenty-years ago. The institutions too are more ready to utilize what the computer has to offer...this is interesting and exciting, but I offer one cautionary note. I hope that in ...these energetic experiments we will not find ourselves slipping into the error of adapting people to computers and adapting institutions to systems. That is exactly the reverse of what we ought to do. Our medical institutions will have to change...they should not change because of the computer, but because of what information systems and humans can do synergistically and because of their changing needs as complex institutions. Perhaps the IAIMS planning opportunity will help us to achieve this desirable outcome."

By 1991, twelve IAIMS grants had been awarded to: Baylor College of Medicine, University of Cincinnati, Duke University, the American College of Obstetrics and Gynecology, Johns Hopkins University, University of Pittsburgh, Dartmouth University, 
the University of Michigan, Rhode Island Hospital, Oregon Health Sciences University, the University of Washington, and Tufts University.

\subsection{Clarifying and Expanding: IAIMS Second Generation}

In 1992, Dr. Lindberg predicted that "the future for the IAIMS concept will be one of growth" [6]. He highlighted three drivers: increased awareness among administrators, health care workers and researchers of the power of computers to provide facile access to information essential to decision making; national interest in the computerized patient record requiring mini-IAIMS for hospital and clinic; and the federal government's High Performance Computing and Communications (HPCC) initiative opening the doors to nation-wide IAIMS collaborations and advanced molecular biology computing, imaging, drug design and educational technologies. Additional details on HPCC appear in separate chapter of this book.

A few months later, NLM introduced a significant revision to the IAIMS program to incorporate lessons from the first decade, and to accommodate the changing environment. The announcement changed the name of the program by replacing academic with advanced. This change recognized the broad applicability of the IAIMS concept and the need to incorporate emerging technologies. The revision reduced the potential duration of funding from ten years to seven. It retained the planning phase from the original program, and fused the modeling and implementation phases into a combined operational phase. It provided the flexibility to include operational elements during planning. The announcement required involvement of all components of the institution, including a clear relationship to clinical aspects of the health sciences; a plan for developing the institution's information management resources, and requisite networks; a functional information policy; designation of leadership with appropriate background and status; timetables for reaching key features of the plan; the ability to provide efficiently bibliographic and related literature; significant participation by the health sciences library; substantial incorporation of elements of HPCC. It included an option to add an IAIMS apprenticeship during the operational phase to build IAIMS workforce capacity.

NLM received over 200 inquiries in the first month after the program announcement, the majority from individual hospitals or associations of hospitals. Richard T. West, MLS, IAIMS Program Officer at the NLM, worked tirelessly to encourage institutions to prepare planning grants and to coach them through the process. Preparation of an application involved organization-wide conversations about leadership, policy and planning that often changed the trajectory of an organization even when the application was not funded. Sites funded for both planning and operational second generation IAIMS projects included City of Hope National Medical Center, Vanderbilt University, University of Medicine and Dentistry of New Jersey, University of Missouri at Columbia, University of Pittsburgh, University of Washington and Yale University. These institutions represented a wide range of organization structure and balance of clinical and academic activities. Each grappled with how to develop an IAIMS that could scale up to enterprise-wide use and evolve in the face of rapidly changing technology and business environments. The key lesson from these projects was the importance of core of enterprise-wide planning and policy formulation functions to guide decision making at all levels of the organization [14]. Support for envisioning the future, organizational development, strategic planning, technology forecasting, development of 
information policy, specification of reference architectures, and development of strategic partnerships has always been critical to any successful IAIMS effort.

\subsection{Toward the Third Generation IAIMS: The AAMC's IAIMS The Next Generation Report}

In 1998, NLM contracted with AAMC to examine the IAIMS concept as articulated by Matheson and Cooper, its implementation in the IAIMS grant program of the NLM, and the effect of the IAIMS grant program on information practices in academic health science centers. The 20-month study process was led by Valerie Florance Ph.D. It included citation analysis, focus groups, site visits and an advisory "think tank group" chaired by Daniel Masys M.D. [15].

The study concluded that then-current academic health sciences centers were richly endowed with networks and electronic resources that were not dreamed of in the 1980s. While the basic mission and goals of academic centers had not changed, the resources that support those missions had become fundamentally different. With access to data, information, and knowledge no longer time and place dependent, new opportunities had emerged to improve the way health care, research and education are carried out. To benefit from these opportunities, attention needed to turn to a new set of challenges.

Among these, two were of special importance. First was the challenge of seamlessly integrating an institution's own information resources with relevant information obtained from sources outside the organization that are not controlled by it. Second, while the challenge of the 1980s was building infrastructure and organizational mechanisms for managing knowledge, the challenge of the 21 st century had become acquisition and shaping of that knowledge such that it binds to effective action. The site visits found participants in the NLM program had valued IAIMS planning; endorsed creation of a flexible pool of funds to direct toward unanticipated opportunities for collaboration; had created branded, sustained activities inside the organization; and had supported development of an academic informatics unit. The report recommended the NLM IAIMS program should be updated to serve as a stimulus for the development and adoption of tools and techniques for information management in the 21 st century. Using technology to enable the application of knowledge - to improve health, to enable good decisions, to enhance learning, to aid discovery and innovation - should become the central focus of IAIMS in the coming decade.

In 2002, NLM responded by revising the scope and structure of the program. IAIMS was redefined as organization-wide or trans-organizational mechanisms that use computer networks to link and relate the published biomedical knowledge base with individual and institutional databases and information files, within and external to an institution. The sequential planning and operational phases were replaced with a portfolio of grant mechanisms to support IAIMS planning, pilot studies, testing or evaluation, operations, or fellowships. Institutions could pick the appropriate entry point for their situation and use multiple IAIMS mechanisms and RO1 mechanisms for related work. The program announcement highlighted context-appropriate information delivery, standards-based information and digital libraries as current areas for focus. Over the next seven years, the NLM funded 15 planning grants, 1 pilot study, 3 test and evaluation projects, and 4 operations grants. 


\subsection{Mainstreaming: NLM's Long Range Plan Charting a course for the $21^{\text {st }}$ century (2006-2016)}

In 2004, Dr. Lindberg invited William Stead M.D. and Hon. Newt Gingrich Ph.D. to cochair the NLM Board of Regents Subcommittee on Planning. Their charge was to develop a new Long-Range Plan for 2006-2016. He narrowed the planning goal to ten years because "few will see the rapidity with which our local science world and our larger geo-political world is changing [16]." Dr. Lindberg accepted the subcommittee's suggestion, based on lessons from IAIMS, that the planning should begin with a longer, quite unconstrained strategic vision. A two-day visioning session in April 2005 explored what the world of health and biomedicine might look like in 2025. The vision for NLM that emerged reflected "the fundamental observation that publication and reading are necessary but insufficient mechanisms to turn knowledge into effective action in the $21^{\text {st }}$ century. A healthcare enterprise that depends primarily on the cognitive capacity and reliability of autonomous individual practitioners and their interpretations of what they read will continue to be error prone and have unacceptably high rates of suboptimal disease prevention, diagnosis, and treatment. In the future the informed and activated consumer will play an increasingly important role in error prevention. A systems approach to health care and public health will depend increasingly on executable knowledge in the form of computerized logic that embodies the collective best understanding and practices for health-related practices. Stated differently, in addition to patients, families, and the public, the Library's fastest growing group of users may be intelligent devices."

This vision jump-started the work of four planning panels focused on: resources and infrastructure; health information for underserved and diverse populations; support for clinical and public health systems; and support for genomic science. These panels developed detailed reports with goals and recommendations for their focus area. Next, a special planning group reviewed these four reports to identify cross-cutting issues for informatics research that emerged from the 4 panels. Then NLM staff and the Board of Regents Planning Subcommittee stepped back and identified four overarching goals: seamless, uninterrupted access to expanding collections of biomedical data, medical knowledge, and health information; trusted information services that promote health literacy, improve health outcomes and reduce health disparities worldwide; integrated biomedical, clinical, and public health information systems that promote scientific discovery and speed the translation of research into practice. This iterative planning process, alternatively zooming out-in-out is an example of Dr. Lindberg applying IAIMS-related techniques directly across the NLM.

\section{IAIMS Governance and Connections}

The first generation IAIMS program focused on technology to help academic medical centers understand the potential of computers and networks to increase information access and use. As understanding of the power of connected computers increased, the IAIMS program shifted to focus on changes in organizational structure and processes, infrastructure and skill sets required to allow management of information as a collective resource and flow of information across boundaries. The second generation focused on organization change within large academic health centers. The third generation expanded 
scope of IAIMS to inter-institutional connections and connections to national or international resources.

From the beginning of the program, IAIMS changed the organizational fabric of participating academic health science centers. Senior leaders came together from across the organization and engaged in conversations with the library director and information technology leaders to develop a credible IAIMS grant proposal. Often these people were at the same table for the first time. The first step involved structuring an interdisciplinary team to lead the IAIMS planning project. IAIMS planning brought people together from different mission areas and levels of the organization to develop a shared vision for the future and a plan to move in that direction. They discussed potential changes in policy and resource allocation to remove barriers to the plan, and their willingness or resistance to the change. IAIMS project structures were often replaced by permanent structural changes during the transition to the operations phase to scale-up organization-wide information management capabilities. Over time, IAIMS organization development principles were hard-wired into the way the organization managed large scale strategic change.

In 1989, six of the institutions funded by the NLM to develop $1^{\text {st }}$ generation IAIMS models self-organized a communal workshop that fostered communication among their teams and identified opportunities to transfer expertise or technology between sites [17.] They defined standards to increase transportability and developed cooperative multicenter projects to evaluate techniques or technologies needed by multiple sites. Four of the institutions were competing for funding in the next year and each institution had to pay their expenses since the workshop was not externally funded. The six sites' Principal Investigators believed they could use what they had learned working across boundaries within their organizations to collaborate across institutions to make the collective effort more than the sum of its parts. The IAIMS Consortium emerged from this workshop. By 1996, the Consortium included 25 institutions interested in IAIMS, broadly defined, not just NLM-funded sites.

The structure of the third generation of the NLM IAIMS grant program assumed that institutions would have a foundation of IAIMS-like organizational development functions and infrastructure in place. The portfolio of IAIMS funding mechanisms supported targeted planning, prototyping, evaluation, and training projects to plug into that foundation. Similarly, the R01 research grant mechanism could be used for IAIMSrelated investigational projects that leveraged an existing IAIMS foundation.

\section{Donald A.B. Lindberg's Impact on IAIMS and the Impact of IAIMS on Donald A.B. Lindberg}

The IAIMS program was continuous throughout Dr. Lindberg's tenure as the Director of the National Library of Medicine. In reviewing materials about IAIMS, it becomes clear that while Dr. Lindberg's leadership had a major impact on IAIMS, the concepts of IAIMS had a major impact on him and his initiatives as Director of NLM.

\subsection{Dr. Lindberg's Leadership Impact on IAIMS}

Dr. Lindberg convened three long-range NLM planning initiatives (1984, 1992, 2004 plus the 1998 IAIMS - The Next Generation AAMC study). While IAIMS-related 
components were included in each planning initiative, their significance grew in prominence in each successive long-range planning process.

During the early Exploring stage, the IAIMS academic sites completed many demonstrations of integrating information and resources. By the Clarifying and Expanding stage, NLM changed its processes for more rapid planning and implementation. At this stage, more organizations were interested in the possibilities of IAIMS. The culmination of the acceptance and spread of the underlying IAIMS-related concepts of was central to the Third Generation, mainstreaming IAIMS-derived ideas through the NLM's long range plan: Charting a course for the $21^{\text {st }}$ century (2006-2016).

\subsection{IAIMS Impact on Dr. Lindberg as Director of the National Library of Medicine}

By 1984, the Medical Library Assistance Act was 20 years old, and a robust network of Regional Medical Libraries was in place. During the course of his NLM leadership, Dr. Lindberg progressively elevated IAIMS from an NLM program to support work by other organizations, to a conceptual framework that he could apply to the NLM system when appropriate. Dr. Lindberg turned aspects of the entire NLM system into a global IAIMS through iterative long-range planning and pragmatic accomplishments. Sample projects and dates support this idea (see additional chapters in this book for details):

- 1986: Unified Medical Language Systems (initiated)

- 1986: Visible Human Project (initiated)

- 1988: National Center for Biotechnology Information (NCBI) (initiated)

- 1996: Stable web browsers led to PubMed and the first internet access to Medline

- 1997: PubMed Central opened free to the world (from MEDLARS-to Medlineto PubMed Central)

- 2000: Clinical Trials Registry

- 2001: RxNorm

\section{Summary}

The IAIMS initiatives significantly changed institutional strategies from a time when biomedical information was managed in silos to a time when biomedical information was extensively integrated and inter-connected with other types of information critical to support effective action. Donald A. B. Lindberg saw the possibilities of IAIMS from the initial Cooper-Matheson report about issues to be solved. He worked to address those issues throughout his tenure as Director of the National Library of Medicine.

\subsection{Paradigm Shift}

Early reports from the 1963 Bloomquist report to the initial AAMC IAIMS study indicated that information users were frustrated by their inability to locate the needed information to do their work. Stead, in a 1997 summary article, indicated that users still found information access problematic, and that "we need to help them, but if we focus on that alone we are putting all of our energy into fixing past decisions about how to use old technology. We have to help those people step past today's problems, to think with us about how they want to work in totally new ways that can be enabled by the kind of 
information access that we can now support. Once that vision is clear, we can see how to move from where we are to where we want to be in a way that solves today's problems incrementally" [14]. IAIMS shifted the paradigm. It was a key initiative that demonstrated the importance of interconnecting people, processes, and technology to provide needed information and actions.

\subsection{Building Infrastructure}

Institutional infrastructure must include technology, people, information, and organizational components. While some institutions may have seen the price tag of integration and coordination as high, the overall costs were potentially similar to what was previously spent in an uncoordinated manner that did not connect or synergize the whole. Without an interconnected infrastructure, users could not have access to the needed information. An IAIMS plan provided institutions with a road map to align individual investments to build a foundation of reusable infrastructure.

\subsection{Working Across Boundaries and Cultures}

Healthcare organizations consist of multiple sub-component organizations. For success with integrated information, organizational sub-components had to work together for success. This meant more effective interconnection of people. IAIMS provided the "push" to internal connections by expecting organizations to work internally as well as externally.

\subsection{Effective Change Management Strategy}

IAIMS essentially provided a strategic change management process for an organization to develop the needed integrated information, services, products, and people. By the cooperation for planning, developing demonstrations and integrating external information, the people in an organization came to appreciate the benefit of IAIMS and the need to work differently and together. Dr. Lindberg saw the possibilities of IAIMS and became its chief proponent externally and internally for the National Library of Medicine.

\section{References}

[1] Bloomquist H. The status of medical school libraries in the United States. J of Med Edu1963 March;38(3):145-163.

[2] Cummings MM, Corning ME. The Medical Library Assistance Act: an analysis of the NLM extramural programs, 1965-1970. Bull. Med. Libr. Ass. 1971 Jul;,59(3):375-391

[3] Stead EA, Jr, Smythe C, Gunn, CO, Littlemeyer, MH. Educational technology for medicine: roles for the Lister Hill Center. J. Med. Educ. 1971 July;46(7): Suppl.1-97

[4] Ash JA, Johnson, FE. IAIMS: An interview with Dick West. J Am Med Inform Assoc. 1999 NovDec;6(6):447-456.

[5] Matheson NW, Cooper JAD. Academic information in the academic health sciences center: roles for the library in information management. J of Med Edu 1982 Oct;57(Part 2):1-93

[6] Lindberg DAB, West RT, Corn M. IAIMS: an overview from the National Library of Medicine. Bull Med Libr Assoc. 1992 Jul;,30(3):244-246

[7] Goldstein RK. Roles for the library in information management. Introduction. Bull Med Libr Assoc. 1983 Oct;71(4):404. 
[8] Braude RM. Roles for the library in information management. Academic information in the academic health sciences center: overview. Bull Med Libr Assoc. 1983 Oct;71(4):405-409.

[9] Lorenzi NM. Roles for the library in information management. Making a dream come true: strategies for medical school libraries. Bull Med Libr Assoc. 1983 Oct;71(4):410-414.

[10] Green EW. Roles for the library in information management. Implications for hospital libraries. Bull Med Libr Assoc. 1983 Oct;71(4): 415-416.

[11] National Library of Medicine. Locating and gaining access to medical and scientific literature / report of Panel 2, National Library of Medicine Long Range Plan. [Internet] Bethesda, Md.: U.S. Dept. of Health and Human Services, National Institutes of Health, 1986. [cited 2021 May 14] Available from: http://resource.nlm.nih.gov/8706344

[12] National Library of Medicine. Medical Informatics / report of Panel 4, National Library of Medicine Long Range Plan. [Internet] Bethesda, Md.: U.S. Dept. of Health and Human Services, National Institutes of Health, 1986. [cited 2021 May 14] Available from: http://resource.nlm.nih.gov/8706364

[13] Planning for integrated academic information management systems. Proceedings of a symposium sponsored by the National Library of Medicine. 1984 October;17, Bethesda, Maryland. U.S. Dept. of Health and Human Services, Public Health Service,52p

[14] Stead WW. The evolution of IAIMS: lessons for the next decade. JAMIA. 1997 March;(2 Suppl);S4-9. Discussion S 10-1

[15] Florance V, Masys DR. Next generation IAIMS: bringing knowledge to effective action. Washington, D.C., Association of American Medical Colleges, 2001.

[16] Charting a course for the 21st century: NLM's long range plan 2006-2016/NLM Board of Regents. [Bethesda, Md.]: U.S. Dept. of Health and Human Services, Public Health Service, national Institutes of Health, National Library of Medicine, 2006.

[17] Stead WW, Roderer N, Zimmerman JL. Successful principles of collaboration: formation of the IAIMS consortium. Acad Med.1991 April;66(4);196-201. 